\title{
Forum
}

\section{Rereading the interdisciplinary mindscape: a response to Redford}

SHAR ACHCHAN D R A LELE

$K_{d}^{\text {entane }}$ ent Redford (2011) offers a reading of the social science discourse on conservation to make a call for greater and better collaboration between social scientists and conservationists. As someone whose initial training as an engineer socialized him into being dismissive about the social sciences, who then struggled to understand and integrate a social science perspective into his work, and who has campaigned for greater interdisciplinarity in environmental research, I find Redford's description of the evolution of his own thinking refreshingly frank and his call for greater openness and collaboration very encouraging. But fostering greater understanding and collaboration across these boundaries may require greater clarity about the categories, roles and values of the disciplines and people involved. Redford characterizes the problem as one of social scientists being too indifferent towards, or too critical of, conservationists, and argues that some of the criticism is based on misreading the conservation(ist) landscape. I suggest that a better understanding of the indifference and criticisms is provided by a clearer separation of the roles of academics versus activists and a fuller appreciation of the different normative stances across social and conservation activists.

Redford characterizes the players involved as 'usconservationists and them-social scientists'. He talks of conservation as a discipline and conservationists' collaboration with social scientists as an interdisciplinary exercise. But this is a flawed categorization liable to lead to confusion and frustration. On the one hand, conservation is not a discipline in the sense we understand disciplines in academia. Conservation is better understood as a 'pragmatic interdiscipline' (Max-Neef, 2005) on par with engineering or farming. Conservation is a goal to which conservationists subscribe. They use generalized knowledge from all relevant academic disciplines, natural and social, plus their own experiential knowledge to decide on particular actions in particular contexts to achieve their particular goal.

On the other hand, social scientists are academics, seeking better explanations or narratives of the social world, just as biologists do for the biological world. When phenomena straddle the social-natural divide, such as wildlife conservation, more integrated and comprehensive (and therefore interdisciplinary) explanations are called for.

SharaChCHANDra Lele Centre for Environment and Development, Ashoka Trust for Research in Ecology and the Environment, Bangalore, India. E-mail slele@atree.org
To generate such explanations one would expect social scientists to collaborate with biologists, not with conservationists per se. Moreover, society's initial expectation of science (not of activism) is that it should be unbiased. Admittedly, in an applied context, this is impossible: every pragmatic interdiscipline, such as farming or conservation, comes with value judgements about what is desirable, such as food production or biodiversity (Lélé \& Norgaard, 1996). Nevertheless, it is reasonable to expect that publicly funded applied science will speak to a broader value base and explore the trade-offs and synergies between one societal goal (e.g. conservation) and other equally legitimate goals (e.g. poverty alleviation). Such science must also be self-consciously critical, questioning the way society gives these goals and academics take them as given. When some social science disciplines such as anthropology and human geography raise such questions of framing and positionality, conservation and other activists become uncomfortable.

Moreover, we should not equate analytical knowledge produced in the sciences with the synthetic knowledge that is required to act-as Redford hints, the latter includes large doses of art. Natural scientists like to believe that their science drives technological change but in fact humans were tinkering with and engineering things long before they developed systematic knowledge about them. Just because social scientists study society it does not follow that they know how to bring about social change, although they probably have a better idea than natural scientists. Similarly, the more reflexive social science disciplines can critique but they cannot necessarily make concrete recommendations for better action. Redford is correct in saying that social scientists are often only finding fault but this is a generic complaint about some sub-disciplines voiced by activists.

By conflating biologists, conservation biologists and conservation activists into one category (conservationists) and similarly conflating economists and anthropologists, pure and applied social scientists, and social activists into another category (social scientists), we set up inappropriate expectations. Conservation activists look at social scientists as instruments of change, expecting them to help unquestioningly in achieving the preordained goal of conservation, then getting irritated when sociologists show more interest in ethnicity than in biodiversity, getting worried when economists say it is 'efficient' to jettison some biodiversity, and getting upset when anthropologists ask 'who speaks for nature?'. 
At the same time this conflation allows us to forget that the role of biologists is not that of conservationists, that biologists working on conservation-related issues must be held up to the standard of broad social relevance and reflexivity that is a must in all applied science. It allows scientists to mix excessively their personal passion for conservation with their work as publicly-funded knowledge providers. Because they care so much about natural ecosystems, conservation biologists often shy away from dispassionate exploration of the links between ecosystems and human well-being, thereby, for instance, calling nutrient cycling an ecosystem service when it is just an internal ecosystem process (Chomitz \& Kumari, 1998), ignoring disservices (Lele, 2009; Dunn, 2010), and using the total economic valuation approach to decision-making only when the result supports the goal of conservation.

Beyond the problem of roles and expectations, there is also a divergence of concerns, and this explains better both the indifference towards, and criticism of, conservation by social scientists and social activists. Notwithstanding the expectation that applied science must speak to a broad set of social goals, each applied science has evolved with a predominant set of values. Applied social scientists have historically focused on social concerns, which, depending on their discipline, may be economic efficiency, poverty alleviation, social justice, democracy, or cultural diversity. When they finally acknowledged the importance of the environment as a driver of social change, different social science disciplines reframed the environmental problem in terms of their traditional concerns. For instance, sustainability became inter-temporal efficiency for economists, and pollution was framed as an environmental justice issue by sociologists.

Biodiversity conservation has been somewhat harder to fit into conventional social goals, partly because of the claim of many conservationists, and natural scientists of that bent, that nature has intrinsic value, thereby putting concern for nature on a higher plane than so-called anthropocentric concerns such as poverty and social justice, or even the material value of nature. Conservationists' interest in other species blinds them to the legitimate interests of the less fortunate members of their own' (Guha, 1997). This is not just a matter of subjectively varying value judgements but one of inconsistency. All those who subscribe to the idea of nature or wild animals having intrinsic value actually implicitly value other things in their own lives: viz., their own survival and material well-being, fairness in society's dealings with them, a respect for property rights and a free press, and so on. They could not exist and function as conservation-oriented citizens if they lived in a society that did not support these other goals. But when it comes to societal action for conservation they do not see these concerns as equally fundamental. At best, they seem to value poverty alleviation and other social concerns in instrumental terms, as a 'conservation tool', as Redford puts it. Social scientists coming from the reflexive tradition have pointed to the inadequacy of conservation as the sole guide for action (Brechin et al., 2002).

Engaging with social activists to get them to think of conservation as a desirable goal requires bringing conservation down to the level of other legitimate societal goals and embracing the idea that one cannot talk about what is good conservation without talking about what is a good society, about what other goals society should subscribe to and where among them conservation ranks. Conservation is not all of environmentalism, and even environmentalismand I say this as a staunch environmentalist-is not all the 'ism' that society needs. Engaging with other social concerns may or may not be useful if one's goal is conservation alone but broadening one's set of concerns is both philosophically consistent and may garner broader support in the long run.

\section{References}

Brechin, S.R., Wilshusen, P.R., Fortwangler, C.L. \& West, P.C. (2002) Beyond the square wheel: toward a more comprehensive understanding of biodiversity conservation as social and political process. Society and Natural Resources, 15, 41-64.

Chomitz, K.M. \& Kumari, K. (1998) The domestic benefits of tropical forests: a critical review. The World Bank Research Observer, 13, 13-35.

DUNN, R.R. (2010) Global mapping of ecosystem disservices: the unspoken reality that nature sometimes kills us. Biotropica, 42, 555-557.

GUHA, R. (1997) The authoritarian biologist and the arrogance of anti-humanism: wildlife conservation in the Third World. The Ecologist, 27, 14-20.

LELE, S. (2009) Watershed services of tropical forests: from hydrology to economic valuation to integrated analysis. Current Opinions in Environmental Sustainability, 1, 148-155.

LÉLÉ, S. \& NorGAARD, R.B. (1996) Sustainability and the scientist's burden. Conservation Biology, 10, 354-365.

Max-Neef, M. (2005) Foundations of transdisciplinarity. Ecological Economics, 53, 5-16.

REDFORD, K.H. (2011) Misreading the conservation landscape. Oryx, $45,324-330$. 